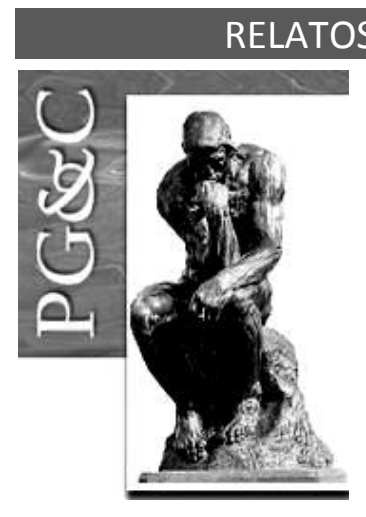

\title{
REDES SOCIAIS E RECURSOS EM EMPRESAS DE BASE TECNOLÓGICA: UM ESTUDO EXPLORATÓRIO
}

\author{
Mário Sacomano Neto \\ Doutor em Engenharia de Produção pela Universidade Federal de São \\ Carlos, Brasil. Professor da Universidade Federal de São Carlos, Brasil. \\ E-mail: sacomanoneto@gmail.com \\ Gabriela Locachevic \\ Mestre em Gestão de Organizações e Sistemas Públicos pela Universidade \\ Federal de São Carlos, Brasil. \\ E-mail: gabrielalocachevic@yahoo.com.br
}

\begin{abstract}
Resumo
Por meio do ensaio teórico-empírico, a presente pesquisa tem como objetivo analisar as redes, no que diz respeito a sua estrutura, nós, ligações e fluxos, e identificar quais são os recursos compartilhados nas relações de empresas pertencentes ao Centro Incubador de Empresas de Software (Softnet). O trabalho é baseado na seleção e interpretação de informações qualitativas secundárias, como livros e artigos científicos, bem como fontes de informação qualitativas primárias, através de entrevista com o gestor da incubadora Softnet e gestores e proprietários de empresas incubadas na Softnet. Esta pesquisa mostra que existe alto grau de colaboração entre os atores envolvidos na incubadora e as instituições e centros de ensino e pesquisa, bem como com outras empresas incubadas, além de evidenciar a intensa relação entre recursos disponíveis e redes sociais de cooperação estabelecidas. Deste modo, este trabalho constatou que a rede social facilita o processo de inovação tecnológica das empresas, através do networking e da cooperação entre empresas incubadas, ressaltando que esta cooperação propicia vantagens que dificilmente seriam alcançadas pelas empresas isoladamente.
\end{abstract}

Palavras-chave: Redes Sociais. Recursos. Incubadora de Empresas. Empresas de Base Tecnológica.

\section{SOCIAL NETWORKS AND RESOURCES IN TECHNOLOGY-BASED COMPANIES: AN EXPLORATORY STUDY}

\begin{abstract}
Through the theoretical-empirical test, the aim of the present study is to analyze the networks, with regard to its structure, nodes, connections and flows, and identify which resources are shared in the relations of companies belonging to the Incubator Center Software Companies (Softnet). This work is based on the selection and interpretation of qualitative secondary information, such as books and scientific articles, as well as primary qualitative information sources, through an interview with the Softnet incubator manager, as well as managers and owners of Softnet incubated companies. This data show that there is a high degree of collaboration between the key involved in the incubator and the institutes and centers of education and research, as well as with other incubated companies, besides highlighting the intense relationship between available resources and social networks of established cooperation. Thus, this study verified that social network facilitates the technological innovation process in companies, through networking and cooperation between incubated companies, emphasizing that this cooperation provides advantages that could hardly be achieved by companies singly.
\end{abstract}

Keywords: Social Networks. Resources. Companies incubator. Technology-Based Companies.

Perspectivas em Gestão \& Conhecimento, João Pessoa, v. 8, n. 2, p. 126-144, mai./ago. 2018. DOI: http://dx.doi.org/10.21714/2236-417X2018v8n2p126

http://periodicos.ufpb.br/ojs2/index.php/pgc. ISSN: 2236-417X. Publicação sob Licença (cc) EY-Nc-ND 


\section{INTRODUÇÃO}

O paradigma da sociedade em rede tem como princípio a tese de que a sociedade atual está organizada em forma de redes, quer os atores utilizem, ou não, suas conexões (GIGLIO; SACOMANO NETO, 2016). Essa sociedade em rede da era da informação se caracteriza, segundo Castells $(1999,2000,2001)$, pela predominância das redes de informação e conhecimento em todos os campos da vida social.

Paralelamente, no contexto acadêmico de estudos organizacionais, observa-se que o tema relativo às redes de cooperação entre organizações tem evoluído constantemente desde a década de 1990. Alguns dos mais importantes periódicos científicos internacionais já realizaram edições especiais dedicadas às redes, como é o caso da revista Organization Studies (1998) e do Academy of Management Journal (2004) (BALESTRIN et al., 2010).

A cooperação entre empresas tem cada vez mais importância nas estratégias de desenvolvimento organizacional e também para a sobrevivência das mesmas no mercado, mas ainda há necessidade de estudos para compreender estes fenômenos (SILVEIRA, 2016).

De acordo com Verschoore (2006), a rede de cooperação é uma organização formada por associados empresariais, que possuem objetivos comuns, prazo ilimitado de existência e uma governança específica e singular para reger as relações de propriedades singulares. 0 termo rede é classificado como um fluxo, movimento, aproximação das mais variadas áreas do conhecimento, afirmando que estas configuram a existência de igualdade e complementariedade entre as partes, formando um conjunto de relações sociais entre um conjunto de atores e também entre eles próprios (ACIOLI, 2007).

Estudos, tanto internacionais (MÜLLER-SEITZ, 2011; LEE; MONGE, 2011; CHASSAGNON, 2014; D'OLIVEIRA, 2016), quanto nacionais (BALESTRIN; VERSCHOORE; REYES JR, 2010; POLETTO; DUARTE; MATA, 2011; FEIJÓ; ZUQUETTO, 2014; SOARES; WEGNER; DOLCI, 2016) mostram a importância das redes de cooperação como estratégias relacionais capazes de propiciar a geração de resultados que transcendem a simples soma dos recursos organizacionais individuais.

A teoria sobre redes sociais pode ser utilizada para estudar como os laços sociais entre os atores de determinada rede poderão afetar o desempenho da empresa. As redes de cooperação têm a capacidade de facilitar a realização de ações conjuntas e a transação de recursos para alcançar objetivos organizacionais (BALESTRIN et al., 2010). Neste contexto integram-se as incubadoras de empresas que, segundo Andino e Fracasso (2005), têm como objetivo promover a criação de empresas e aumentar sua possibilidade de sucesso ou sobrevivência, constituindo espaços que propiciam condições técnicas e gerenciais apropriadas para as empresas se desenvolverem nos seus primeiros anos, onde ocorre o maior índice de mortalidade. Trata-se de espaço baseado em torno de uma relação contínua com universidades, que proporciona espaço físico, infraestrutura, conhecimentos técnicos, pesquisa e ajuda administrativa para as empresas conseguirem se inserir no mercado cada vez mais competitivo.

Entre as diversas ações que buscam alavancar a inovação e o desenvolvimento tecnológico está a promoção de Empresas de Base Tecnológica (EBTs). Essas empresas, conforme Cheng et al. (2007), podem ser vistas como as grandes empresas do século XXI e como um dos principais motores do progresso, não só científico, mas social e econômico das nações.

Segundo Cortes et al. (2005), entende-se que EBTs, analisadas sob a perspectiva das redes sociais, podem ser caracterizadas como redes de produção e de oportunidade e acesso, por serem estruturas em que as relações de poder são minimizadas, os agentes são horizontais e a maioria das relações, em particular as orientadas a Pesquisa e Desenvolvimento (P\&D), é de cooperação, difundindo-se pela rede informações, proporcionando troca de conhecimento

Perspectivas em Gestão \& Conhecimento, João Pessoa, v. 8, n. 2, p. 126-144, mai./ago. 2018. 
para inovação e tecnologia. Nessa dinâmica, o nível da cooperação é variável dependente do grau de confiança que se estabelece entre os atores.

Assim, o problema de pesquisa proposto para este trabalho foi: como e porque ocorrem o estabelecimento de redes de relacionamento e o compartilhamento de recursos entre as EBTs da incubadora de empresas. Foram estudados também quais são os recursos existentes nestas redes sociais e quais os relacionamentos das redes.

Nos últimos anos, as incubadoras têm-se destacado por ser um dos agentes mais ativos e comprometidos com a criação e dinamização de empresas de base tecnológica (LEITE, 2006). Ressalta-se que, nesse cenário, cerca de $70 \%$ das incubadoras brasileiras declaram possuir foco tecnológico (ANPROTEC, 2012).

O presente estudo se justifica pela importância das redes sociais para o progresso e evolução de empresas incubadas e, portanto, recentes no mercado. Além disso, a teoria dos recursos engloba os aspectos de alianças estratégicas, indispensáveis para o desenvolvimento de produtos de base tecnológica que envolve diferentes especialidades.

\section{REFERENCIAL TEÓRICO}

\subsection{Redes Sociais}

Desde os arranjos sociais mais simples até as estruturas mais complexas, as pessoas interagem entre si em matrizes de relacionamentos de redes em diferentes dimensões (NOHRIA; ECCLES, 1992). Estas redes podem ser compostas por pessoas ou organizações, ambos os casos considerados nós de redes de interação social que se ligam por meio de relacionamentos (CASTILLA et al., 2000). A perspectiva das redes, então, é algo que deve ser considerado como inerente à vida social, especialmente, quando se observa o fato de que não é viável (ou mesmo possível) para um dado ator - seja ele uma pessoa ou uma organização viver de forma completamente independente e isolada de outros e em múltiplas instâncias. Tudo e todos estão interligados de alguma forma (BARABÁSI, 2003).

As redes sociais ou networks vêm sendo evidenciadas por autores como Mizruchi (2006), Kimura, Teixeira e Godoy (2004) e por Balestrin e Vargas (2004) por possibilitarem ao empreendedor manter contatos, ampliar as possibilidades de encontro de oportunidades de negócios, além de se configurar como forma para as empresas alcançarem competitividade nos mercados por meio do ordenamento de relacionamentos. Assim sendo, de acordo com Jesus e Machado (2009), considerando que a rede social se baseia nas relações interpessoais, acredita-se que ela é um elemento presente e determinante capaz de influir no comportamento competitivo das organizações.

A Teoria de Redes pode ser entendida como uma análise complexa das interações entre os atores envolvidos, atores esses que podem ser pessoas, organizações, meio ambiente, a partir do instante em que haja algum tipo de troca entre eles, sendo tangíveis (bens, materiais) ou intangíveis (ideias, valores) (FERREIRA; VITORINO FILHO, 2010).

Conforme Mizruchi (2006), as redes sociais influenciam o comportamento de indivíduos e grupos, onde a ação humana é afetada pelas relações sociais em que os agentes estão imersos. Com base nesta afirmação, Kimura, Teixeira e Godoy (2004) destacam que essas interações sociais aprimoram ou restringem o acesso a recursos, pois, incorporando capital social, geram externalidades como conhecimentos sobre o comportamento de outros agentes, o conhecimento sobre o mercado como preços e tecnologias, e sobre o benefício da ação coletiva.

Assim, as redes unem os indivíduos organizando-os de forma igualitária e democrática e em relação aos objetivos que eles possuem em comum.

Perspectivas em Gestão \& Conhecimento, João Pessoa, v. 8, n. 2, p. 126-144, mai./ago. 2018. 
Portanto, de acordo com Ferreira e Vitorino Filho (2010), as redes sociais em sua particularidade estão desencadeando uma fonte de inovações aos fatos sociais, econômicos, políticos, entre outros, sendo que, esse tema em potencial, não possui uma raiz totalmente definida e suas contribuições também estão cada vez mais sendo ampliadas, pois essas conexões e restrições de relacionamentos podem ser invertidas a qualquer momento, sendo as redes criadas, intensificadas, destituídas, construídas a partir de outras, destruídas e reconstruídas.

\subsection{Recursos em Redes}

Considerando o objeto de estudo desta pesquisa, a teoria dos recursos contribuiu explicando o porquê de ocorrerem associações e ligações com outras empresas, buscando assim as vantagens e benefícios dos recursos específicos e próprios de outras organizações.

A proposição central da teoria dos recursos é que a fonte da vantagem competitiva encontra-se, primeiramente, nos recursos e competências desenvolvidos e controlados pelas empresas e, apenas, secundariamente, na estrutura das indústrias nas quais elas se posicionam (WERNERFELT, 1984; PETERAF, 1993).

A teoria dos recursos empresariais parece particularmente apropriada para examinar alianças estratégicas, visto que as firmas usam tais alianças com a intenção de ganhar acesso aos recursos valiosos de outras empresas (KLOTZLE, 2002). Em razão disso, os recursos de uma empresa oferecem certa base relevante para o estudo de alianças estratégicas, alianças estas que só são possíveis se existir certa diferenciação ou complementaridade entre os recursos das empresas envolvidas na criação de uma relação de cooperação.

A cooperação entre as empresas permite que elas tenham acesso à informação, recursos, mercados e tecnologias, com vantagens de aumentar seus conhecimentos, obter economias de escala e escopo, compartilhar riscos e combinar competências com outras empresas, tornando-as mais aptas a explorar novas oportunidades do mercado (GULATI; NOHRIA; ZAHEER, 2000).

Os recursos, de acordo com Grant (1991) e Hill e Jones (1996), referem-se aos meios físicos, financeiros, humanos, tecnológicos e organizacionais e à reputação da empresa, podendo se dividir em tangíveis, tais como terrenos, edifícios e máquinas, e intangíveis, tais como marca, reputação da empresa, confiança dos clientes, informações sobre clientes e concorrentes, patentes e know-how.

Quanto às capacidades, se referem às habilidades (ou talento) para utilizar os recursos de uma maneira combinada e coordenada com as pessoas e com os processos organizacionais, de uma forma que seja possível levar a cabo os fins desejados pela organização (AMIT; SCHOEMAKER, 1993).

Buscando trazer mais didática ao presente estudo e considerando que há uma diversidade de definições sobre os temas até então abordados, o Quadro 1 traz os conceitos de redes e recursos que ancoraram a pesquisa e as variáveis que nortearam o levantamento de campo.

Quadro 1 - Conceito de redes e recursos e respectivas categorias de análise

\begin{tabular}{|l|l|}
\hline \multicolumn{1}{|c|}{ Conceitos } & \multicolumn{1}{c|}{ Categorias de análise } \\
\hline $\begin{array}{l}\text { Redes sociais: interações entre os atores } \\
\text { envolvidos em relacionamentos } \\
\text { organizacionais, a partir do instante em que } \\
\text { haja algum tipo de troca entre eles, sendo }\end{array}$ & Nós, estruturas, ligações e fluxos \\
\hline
\end{tabular}

Perspectivas em Gestão \& Conhecimento, João Pessoa, v. 8, n. 2, p. 126-144, mai./ago. 2018. 


\begin{tabular}{|l|l|}
\hline tangíveis ou intangíveis & \\
\hline $\begin{array}{l}\text { Recursos: meios físicos, financeiros, } \\
\text { humanos, tecnológicos e organizacionais e } \\
\text { reputacionais da empresa, podendo se } \\
\text { dividir em tangíveis, e intangíveis }\end{array}$ & $\begin{array}{l}\text { Recursos humanos, físicos, financeiros, } \\
\text { tecnológicos, reputacionais e organizacionais }\end{array}$ \\
\hline
\end{tabular}

Fonte: o autor

No âmbito da pesquisa de análise de redes sociais, rede significa um grupo de atores ou nós que possuem relações com outros. Essas relações ou vínculos se caracterizam por fluxos de informação. Fluxos, nós e vínculos constituem-se nos elementos básicos de uma rede. Nós são atores agrupados em torno de um objetivo comum e vínculos são laços existentes entre esses atores. A direção desse vínculo é expressa pelo fluxo, que pode ser unidirecional, quando não há reciprocidade na relação, ou bidirecional, quando há reciprocidade, ou seja, os atores citam-se mutuamente (NORMAN; ALEJANDRO, 2005).

Para Barney (1991), os recursos de uma firma consistem em todos os ativos tangíveis e intangíveis, humanos e não humanos possuídos e controlados por ela e que the permitem agregar valor a seus produtos e serviços. $\mathrm{O}$ autor cita três categorias principais de recursos: os físicos, os humanos e os organizacionais. Grant (1991), por sua vez, inclui ainda os recursos tecnológicos, financeiros e reputacionais.

\section{METODOLOGIA}

O ambiente onde a pesquisa foi realizada é constituído de uma incubadora de empresas instalada na Fundação ParqTec de São Carlos, a Softnet, e de três empresas pertencentes a esta incubadora, a Cubo TI, a Onion e a Neolnfinito.

A escolha da Fundação ParqTec se justifica pelo fato de ser a entidade pioneira que surgiu da primeira política pública para institucionalizar a transferência de tecnologia da academia para o setor produtivo.

Com base nos objetivos desta pesquisa, trata-se aqui de uma pesquisa descritiva e qualitativa, pois buscou analisar as redes de relacionamentos e identificou os recursos compartilhados entre as EBTs da incubadora de empresas Softnet.

A pesquisa realizada caracteriza-se como essencialmente qualitativa. De acordo com Cassell e Symon (1995), a pesquisa qualitativa apresenta as seguintes características: foco na interpretação, ao invés da quantificação; ênfase na subjetividade, ao invés de objetividade; flexibilidade no processo de condução da pesquisa e preocupação com o contexto. Além disso, este estudo é exploratório, porquanto, como em Segatto-Mendes (1996), tem uma natureza exploratória, por buscar uma compreensão da natureza geral do problema/situação.

A metodologia proposta, considerando o escopo desta pesquisa (amplitude e profundidade do estudo) estruturou-se em estudo de caso, mais especificamente multicaso, de caráter descritivo e exploratório, envolvendo pesquisa nas empresas da incubadora Softnet, ancorado na literatura de Yin (2001), segundo o qual os estudos de casos geram hipóteses e teorias.

\subsection{Coleta de Dados}

Como toda pesquisa implica o levantamento de dados de variadas fontes, o trabalho foi baseado na seleção e interpretação de informações qualitativas secundárias, como livros e

Perspectivas em Gestão \& Conhecimento, João Pessoa, v. 8, n. 2, p. 126-144, mai./ago. 2018. 
artigos científicos; bem como fontes de informação qualitativas primárias, através de entrevistas com o gestor da incubadora Softnet e gestores e proprietários de empresas incubadas na Softnet, quais sejam, a Cubo TI, a Onion Tecnologia e a Neolnfinito.

A coleta de dados foi realizada por meio de pesquisa bibliográfica e documental e entrevista semiestruturada, com apoio de um roteiro de entrevista. A entrevista semiestruturada tem como característica um roteiro com perguntas abertas, que apresenta flexibilidade na ordem de exposição das questões ao entrevistado. Além disso, o entrevistador pode realizar perguntas adicionais para compreender melhor o assunto em discussão.

Independente da abordagem teórica adotada, de acordo com Manzini (2004), principalmente quando a entrevista é do tipo semiestruturada, são necessários cuidados que envolvem questões da linguagem e o roteiro a ser utilizado necessita ser planejado cuidadosamente.

Os roteiros de entrevista foram construídos tomando por base os autores Manzini (2003), Rea e Parker (2000) e Seidman (1988), que definem alguns cuidados e pontos que necessitam de atenção do pesquisador, como a linguagem, a forma e sequência das perguntas realizadas.

Para tratamento dos dados obtidos foi utilizada a técnica de análise de conteúdo, mais especificamente a análise temática, ou seja, aquela que utiliza o tema como unidade de análise, pois, de acordo com Bardin (2011), as respostas a questões abertas, as entrevistas (não diretivas ou mais estruturadas) individuais ou de grupo, podem ser, e são frequentemente, analisados tendo o tema por base.

As entrevistas semiestruturadas, seguindo o roteiro pré-definido, foram realizadas com o gestor da incubadora Softnet e com os empresários incubados. Foram elaborados dois roteiros (Apêndice A e B), divididos em quatro temas centrais: caracterização da empresa/incubadora; agentes institucionais públicos, universidades, empresas e atores relacionados à incubadora/empresa; rede de relações da incubadora com as empresas e; os recursos da empresa.

\section{RESULTADOS}

A partir das entrevistas com o gerente da incubadora de empresas Softnet e com três empreendedores de empresas incubadas, foi possível identificar e fazer uma caracterização das redes e dos recursos da incubadora e das empresas, considerando os pontos levantados na conversa com os gestores, bem como as fontes secundárias de pesquisa e a literatura.

\subsection{Caso Softnet}

O ParqTec implantou em 6 de maio de 1984 a primeira incubadora temática, chamada de Centro Incubador de Empresas de Software - Softnet, que tem como objetivo apoiar a criação e a consolidação de empresas de Tecnologia da Informação e Comunicação (TIC) na Região de Inovação de São Carlos (PARQTEC, 2015).

Instalado em São Carlos, o ParqTec tem contribuído de maneira significativa na construção de uma vibrante Região de Inovação constituída por universidades públicas e privadas, centros de pesquisas, órgãos de governo e por um conjunto de mais de 180 EBTs atuando nas áreas de TIC; Novos Materiais; Instrumentação Eletrônica; Automação \& Robótica; Química Fina e Óptica (PARQTEC, 2015).

Para a presente pesquisa, considerando as categorias de recursos citadas por Barney (1991) e Grant (1991), relacionamos os recursos físicos ao apoio e estrutura física fornecidos pela Fundação ParqTec e pela incubadora Softnet; os recursos humanos referem-se ao trânsito de profissionais de universidades e centros de pesquisas; os recursos organizacionais são

Perspectivas em Gestão \& Conhecimento, João Pessoa, v. 8, n. 2, p. 126-144, mai./ago. 2018. 
concernentes tanto ao networking com empresas e clientes, como também o apoio fornecido pela fundação nos serviços de assessoria de imprensa, correio, segurança e limpeza; já os recursos tecnológicos se conectam às pesquisas e estudos desenvolvidos em ambientes de pesquisa, bem como ao know-how e especialidades de empresas parceiras; os recursos financeiros remetem tanto ao apoio financeiro prestado pela Fundação ParqTec à incubadora Softnet, bem como aos financiamentos concedidos às empresas através das agências de fomento; e por fim, recursos reputacionais correspondem à valorização da marca e da imagem da incubadora e das empresas pelo fato de estarem ligadas ao nome da Fundação ParqTec.

Em um ambiente onde a inovação tecnológica representa um ponto chave para a competitividade, as empresas passam, então, a buscar parceiros que as auxiliem nas estratégias tecnológicas. Neste contexto, as universidades e os agentes políticos constituem elementos centrais para a competitividade, o primeiro por possuir recursos humanos com alta capacidade intelectual e, o segundo, pela possibilidade de investimento financeiro. Os agentes políticos aqui são considerados tanto aqueles detentores de cargo eletivo bem como todos aqueles que prestam qualquer tipo de serviço ao Estado.

O Quadro 2 expõe as redes identificadas na incubadora Softnet, bem como os fluxos e recursos gerados nas relações.

Quadro 2 - Quadro descritivo das redes identificadas na Incubadora Softnet, dos fluxos gerados e dos recursos gerados na relação

\begin{tabular}{|c|c|c|c|}
\hline & Redes identificadas & Fluxos gerados & $\begin{array}{c}\text { Recursos gerados na } \\
\text { relação }\end{array}$ \\
\hline \multirow{8}{*}{ Softnet } & $\begin{array}{l}\text { Associação para Promoção da } \\
\text { Excelência do Software } \\
\text { Brasileiro (Softex) }\end{array}$ & $\begin{array}{l}\text { Articulação de parceiros da } \\
\text { iniciativa privada, governo e } \\
\text { academia }\end{array}$ & $\begin{array}{l}\text { Recursos } \\
\text { organizacionais e } \\
\text { reputacionais }\end{array}$ \\
\hline & $\begin{array}{l}\text { Universidade de São Paulo } \\
\text { (USP) }\end{array}$ & $\begin{array}{l}\text { Trânsito de profissionais e } \\
\text { pesquisadores e de } \\
\text { conhecimento }\end{array}$ & $\begin{array}{l}\text { Recursos humanos e } \\
\text { tecnológicos }\end{array}$ \\
\hline & $\begin{array}{l}\text { Universidade Federal de São } \\
\text { Carlos (UFSCar) }\end{array}$ & $\begin{array}{l}\text { Trânsito de profissionais e } \\
\text { pesquisadores e de } \\
\text { conhecimento }\end{array}$ & $\begin{array}{l}\text { Recursos humanos e } \\
\text { tecnológicos }\end{array}$ \\
\hline & $\begin{array}{l}\text { Empresa Brasileira de Pesquisa } \\
\text { Agropecuária (Embrapa) }\end{array}$ & $\begin{array}{l}\text { Trânsito de profissionais e } \\
\text { pesquisadores e de } \\
\text { conhecimento }\end{array}$ & $\begin{array}{l}\text { Recursos humanos e } \\
\text { tecnológicos }\end{array}$ \\
\hline & $\begin{array}{l}\text { Prefeitura Municipal de São } \\
\text { Carlos }\end{array}$ & $\begin{array}{l}\text { Apoio a eventos e divulgação } \\
\text { da incubadora e das } \\
\text { empresas }\end{array}$ & $\begin{array}{l}\text { Recursos } \\
\text { organizacionais }\end{array}$ \\
\hline & Fundação ParqTec & $\begin{array}{l}\text { Apoio e estrutura física, sala } \\
\text { de reuniões e negócios, } \\
\text { assessoria de imprensa, } \\
\text { manutenção financeira da } \\
\text { incubadora }\end{array}$ & $\begin{array}{l}\text { Recursos físicos, } \\
\text { financeiros, } \\
\text { reputacionais e } \\
\text { organizacionais }\end{array}$ \\
\hline & $\begin{array}{l}\text { Conselho Nacional de } \\
\text { Desenvolvimento Científico e } \\
\text { Tecnológico (CNPq) }\end{array}$ & Apoio e financiamento & Recursos financeiros \\
\hline & $\begin{array}{l}\text { Secretaria de } \\
\text { Desenvolvimento Econômico, } \\
\text { Ciência, Tecnologia e Inovação } \\
\text { do Estado de São Paulo }\end{array}$ & $\begin{array}{l}\text { Atração de investimentos e } \\
\text { geração de novas empresas }\end{array}$ & $\begin{array}{l}\text { Recursos } \\
\text { organizacionais e } \\
\text { financeiros }\end{array}$ \\
\hline
\end{tabular}

Perspectivas em Gestão \& Conhecimento, João Pessoa, v. 8, n. 2, p. 126-144, mai./ago. 2018. 


\begin{tabular}{|l|l|l|l|}
\hline \multirow{2}{*}{} & (SDECTI) & \\
\cline { 2 - 3 } & $\begin{array}{l}\text { Serviço Brasileiro de Apoio às } \\
\text { Micro e Pequenas Empresas } \\
\text { (SEBRAE) }\end{array}$ & $\begin{array}{l}\text { Firmado convênio para } \\
\text { prestação de serviços de } \\
\text { consultoria às empresas da } \\
\text { incubadora }\end{array}$ & $\begin{array}{l}\text { Recursos } \\
\text { organizacionais }\end{array}$ \\
\hline
\end{tabular}

Fonte: o autor

A Softnet é uma subsede da Associação para Promoção da Excelência do Software Brasileiro (Softex). A Softex executa, desde 1996, iniciativas de apoio, desenvolvimento, promoção e fomento para impulsionar a Indústria Brasileira de Software e Serviços de TI, uma das maiores em todo o mundo, conhecida por sua criatividade, competência e fonte de talentos. Dessa forma, trata-se de relação que gera articulação com parceiros da iniciativa privada, governo e academia, garantindo recursos organizacionais (networking com empresas e clientes) e reputacionais (valorização da marca e imagem da incubadora).

Considerando as universidades e centros de pesquisa, ou seja, UFSCar, USP e Embrapa, tratam-se de vínculos com trânsito de profissionais e pesquisadores e de conhecimento, onde fluem recursos humanos e tecnológicos.

Com a Prefeitura Municipal, compartilham-se recursos organizacionais relacionados ao apoio a eventos e divulgação da incubadora e das empresas.

Já com relação à Fundação ParqTec, são oferecidos recursos físicos, financeiros, reputacionais e organizacionais, compartilhando com a incubadora e com as empresas apoio e estrutura física, sala de reuniões e negócios, assessoria de imprensa e manutenção financeira da incubadora.

O CNPq partilha recursos financeiros com relação ao apoio e financiamentos às empresas incubadas e incubadora.

A Secretaria de Desenvolvimento Econômico, Ciência, Tecnologia e Inovação do Estado de São Paulo, através dos fluxos de recursos organizacionais e financeiros, garante a atração de investimentos e geração de novas empresas.

Por fim, identificou a rede do SEBRAE, com fluxo de recursos organizacionais que consiste em convênio firmado para prestação de serviços de consultoria às empresas da incubadora.

\subsection{Caso Empresas}

Os Quadros 3, 4 e 5 expõem, respectivamente, as redes identificadas, os fluxos e recursos gerados nas relações das empresas estudadas, quais sejam, Cubo TI, Onion Tecnologia e Neolnfinito.

Quadro 3 - Redes identificadas na Cubo TI, dos fluxos gerados e dos recursos gerados na relação

\begin{tabular}{|l|l|l|l|}
\hline & \multicolumn{1}{|c|}{ Redes identificadas } & \multicolumn{1}{|c|}{ Fluxos gerados } & \multicolumn{1}{c|}{$\begin{array}{c}\text { Recursos gerados na } \\
\text { relação }\end{array}$} \\
\hline $\begin{array}{l}\text { Cubo } \\
\text { TI }\end{array}$ & Softnet & $\begin{array}{l}\text { Networking, valorização da } \\
\text { marca, estrutura e apoio } \\
\text { físico, acesso a potenciais } \\
\text { novos clientes e } \\
\text { consumidores }\end{array}$ & $\begin{array}{l}\text { Recursos físicos, } \\
\text { organizacionais e } \\
\text { reputacionais }\end{array}$ \\
\hline
\end{tabular}

Perspectivas em Gestão \& Conhecimento, João Pessoa, v. 8, n. 2, p. 126-144, mai./ago. 2018. 


\begin{tabular}{|l|l|l|l|}
\hline SEBRAE & Consultoria empresarial & Recursos organizacionais \\
\cline { 2 - 4 } & $\begin{array}{l}\text { Onion Tecnologia e outras } \\
\text { empresas }\end{array}$ & $\begin{array}{l}\text { Parceria em pesquisas para } \\
\text { desenvolvimento de novos } \\
\text { produtos }\end{array}$ & $\begin{array}{l}\text { Recursos humanos e } \\
\text { tecnológicos }\end{array}$ \\
\cline { 2 - 4 } & $\begin{array}{l}\text { Universidades e Centros } \\
\text { de Pesquisa }\end{array}$ & $\begin{array}{l}\text { Trânsito de profissionais e } \\
\text { pesquisadores e de } \\
\text { conhecimento }\end{array}$ & $\begin{array}{l}\text { Recursos humanos e } \\
\text { tecnológicos }\end{array}$ \\
\hline
\end{tabular}

Fonte: o autor

A Cubo TI Soluções na Medida Certa é uma empresa especialista em Marketing Digital, com foco em resultados na marca do cliente. Tem como objetivo planejar as ações de marketing digital que o cliente necessita e propor soluções. Com profissionais capacitados, a Cubo TI utiliza as tecnologias mais avançadas do mercado na elaboração de projetos para garantir o melhor resultado e visualização da marca. Elaboram projetos de marketing digital com criatividade para que o público alvo da empresa esteja bem informado sobre seus produtos, serviços, novidades, acarretando assim o sucesso da empresa.

Com relação ao vínculo com a incubadora Softnet, ocorre o compartilhamento de recursos físicos, organizacionais e reputacionais, garantindo resultados relacionados com a estrutura física e o apoio proporcionados pela incubadora, a valorização da marca que passa a ser vinculada a credibilidade e qualidade da Fundação ParqTec e o networking gerado pelo pertencimento à incubadora, relacionado com o acesso a novos potenciais clientes $e$ consumidores.

O SEBRAE garante a Cubo TI consultoria empresarial através do fluxo de recursos organizacionais.

Já o relacionamento existente com a Onion Tecnologia e outras empresas geram fluxos de recursos humanos e tecnológicos, com o curso de profissionais e de tecnologias para a parceria em pesquisas no desenvolvimento de novos produtos.

Por fim, universidades e centros de pesquisas, através do compartilhamento de recursos humanos e tecnológicos, geram o trânsito de profissionais e pesquisadores e de tecnologias.

Quadro 4 - Redes identificadas na Onion Tecnologia, dos fluxos gerados e dos recursos gerados na relação

\begin{tabular}{|l|l|l|l|}
\hline & \multicolumn{1}{|c|}{ Redes identificadas } & \multicolumn{1}{|c|}{ Fluxos gerados } & \multicolumn{1}{c|}{$\begin{array}{c}\text { Recursos gerados na } \\
\text { relação }\end{array}$} \\
\hline \multirow{4}{*}{$\begin{array}{l}\text { Onion } \\
\text { Tecnologia }\end{array}$} & Softnet & $\begin{array}{l}\text { Networking, valorização } \\
\text { da marca, estrutura e } \\
\text { apoio físico, acesso a } \\
\text { potenciais novos clientes } \\
\text { consumidores }\end{array}$ & $\begin{array}{l}\text { Recursos físicos, } \\
\text { organizacionais e } \\
\text { reputacionais }\end{array}$ \\
\cline { 2 - 4 } & SEBRAE & Consultoria empresarial & Recursos organizacionais \\
\cline { 2 - 4 } & $\begin{array}{l}\text { Cubo TI, Neolnfinito e } \\
\text { outras empresas }\end{array}$ & $\begin{array}{l}\text { Parceria em pesquisas } \\
\text { para desenvolvimento de } \\
\text { novos produtos }\end{array}$ & $\begin{array}{l}\text { Recursos humanos e } \\
\text { tecnológicos }\end{array}$ \\
\cline { 2 - 5 } & FAPESP & $\begin{array}{l}\text { Financiamento de } \\
\text { pesquisas }\end{array}$ & Recursos financeiros \\
\hline
\end{tabular}

Perspectivas em Gestão \& Conhecimento, João Pessoa, v. 8, n. 2, p. 126-144, mai./ago. 2018. 


\begin{tabular}{|l|l|l|l|}
\hline USP e UFMS & $\begin{array}{l}\text { Trânsito de profissionais e } \\
\text { pesquisadores e de } \\
\text { conhecimento }\end{array}$ & $\begin{array}{l}\text { Recursos humanos e } \\
\text { tecnológicos }\end{array}$ \\
\hline
\end{tabular}

Fonte: o autor

A Onion Tecnologia é uma empresa que fornece soluções em desenvolvimento web, com sistemas na web confiáveis para a necessidade dos negócios, controle de estoques, vendas, geração de relatórios através de um sistema em uma nuvem com alta disponibilidade; desenvolvimento mobile, através de aplicativos, divulgando produtos e interagindo com clientes; e big data, utilizando dados a favor do cliente, com serviços personalizados, identificando nichos inexplorados, otimizando processos de vendas, entre outros benefícios.

Da mesma forma como na Cubo $\mathrm{TI}$, a rede formada pela Onion Tecnologia e a incubadora Softnet movimenta recursos físicos, organizacionais e reputacionais, ou seja, networking, valorização da marca, estrutura e apoio físico e acesso a potenciais novos clientes e consumidores.

Com o SEBRAE, a rede garante a consultoria empresarial proporcionada pelo convênio firmado entre a incubadora e a instituição.

A Cubo TI, a Neolnfinito e outras empresas são relações com fluxos de recursos humanos e tecnológicos, que visam compartilhar o know-how, a experiência e a especialidade de cada organização, gerando assim parcerias em pesquisas para o desenvolvimento de novos produtos.

Já o estabelecimento de redes com agências de fomento busca, principalmente, recursos financeiros através do financiamento de pesquisas.

Finalizando a rede identificada da Onion Tecnologia, o compartilhamento de recursos humanos e tecnológicos com a Universidade de São Paulo (USP) e Universidade Federal do Mato Grosso do Sul (UFMS) é realizado através do trânsito de profissionais altamente qualificados e de conhecimento, para suprir especialidades não constantes dentro da empresa.

Quadro 5-Redes identificadas na Neolnfinito, dos fluxos gerados e dos recursos gerados na relação

\begin{tabular}{|c|c|c|c|}
\hline & Redes identificadas & Fluxos gerados & $\begin{array}{l}\text { Recursos gerados na } \\
\text { relação }\end{array}$ \\
\hline \multirow{4}{*}{ Neolnfinito } & Softnet & $\begin{array}{l}\text { Networking, valorização } \\
\text { da marca, estrutura e } \\
\text { apoio físico, acesso a } \\
\text { potenciais novos clientes } \\
\text { e consumidores }\end{array}$ & $\begin{array}{l}\text { Recursos físicos, } \\
\text { organizacionais e } \\
\text { reputacionais }\end{array}$ \\
\hline & SEBRAE & Consultoria empresarial & Recursos organizacionais \\
\hline & $\begin{array}{l}\text { Onion e outras } \\
\text { empresas }\end{array}$ & $\begin{array}{l}\text { Parceria em pesquisas } \\
\text { para desenvolvimento de } \\
\text { novos produtos }\end{array}$ & $\begin{array}{l}\text { Recursos humanos e } \\
\text { tecnológicos }\end{array}$ \\
\hline & UFSCar & $\begin{array}{l}\text { Transferência de } \\
\text { profissionais e } \\
\text { pesquisadores e de } \\
\text { conhecimento }\end{array}$ & $\begin{array}{l}\text { Recursos humanos e } \\
\text { tecnológicos }\end{array}$ \\
\hline
\end{tabular}

Fonte: o autor

Perspectivas em Gestão \& Conhecimento, João Pessoa, v. 8, n. 2, p. 126-144, mai./ago. 2018. 
A Neolnfinito é uma start-up de base tecnológica que desenvolve, integra e comercializa aplicativos analíticos para auxiliar tomadores de decisão a encontrarem as melhores soluções nos menores tempos em ambientes de finanças, manufatura e logística. Essas soluções agilizam processos de decisão, diminuem custos e otimizam recursos escassos e caros, transformando dados em valor, fazendo ciência aplicada à decisão.

Do mesmo modo como nas outras empresas pesquisadas, a rede com a Softnet movimenta os recursos físicos, organizacionais e reputacionais. Com isso, a Neolnfinito tem acesso ao networking, ao apoio e estrutura física da incubadora, a valorização da marca e a possibilidade de obtenção de potenciais novos clientes e consumidores.

Os recursos organizacionais compartilhados na rede com o SEBRAE relacionam-se com a consultoria empresarial nas mais diversas áreas (marketing, finanças, formação de preços) suprindo uma necessidade recorrente entre os empreendedores, que possuem excelente formação técnica, mas pouco conhecimento empresarial.

Os fluxos gerados a partir da conexão com a Onion Tecnologia e outras empresas relacionam-se com recursos humanos e tecnológicos. Em razão da demanda trazida por clientes, ocorrem parcerias com outras empresas para desenvolvimento de novos produtos com o objetivo de suprir especialidades não encontradas no quadro da própria empresa.

Por fim, os recursos humanos e tecnológicos frutos do relacionamento com a UFSCar geram o trânsito de conhecimento e, por consequência, possibilidades de criação de produtos ou serviços inovadores. Além disso, ocorre também a circulação de profissionais altamente qualificados vindos de universidades e centros de pesquisa.

\section{ANÁLISE DOS RESULTADOS}

Em consonância com Duarte (2004), ao longo de todo o processo de análise, o material empírico foi interpretado à luz da literatura científica de referência, que produz teoria articulada ao conjunto de produções científicas com o qual se identifica. No que diz respeito à interpretação das entrevistas semiestruturadas, como explica Duarte (2004), a análise temática é um recurso que "encurta o caminho" do pesquisador, sobretudo quando se trata de pesquisadores iniciantes. Nesse caso, pode-se tomar o conjunto de informações recolhidas junto aos entrevistados e organizá-las, primeiramente, em três ou quatro grandes eixos temáticos, articulados aos objetivos centrais da pesquisa.

As vantagens em fazer parte de um espaço inovador e único como a incubadora de empresas Softnet foi salientada por todos os entrevistados. Considerando a cooperação e parceria da Onion e da Neolnfinito com as universidades, conforme é explicado por Caldera e Debande (2010), a presença de um parque tecnológico tem profunda influência na comercialização da pesquisa acadêmica, ou seja, que a concentração de empresas de base tecnológica tem uma importante participação na valorização da pesquisa das universidades, sendo que um parque tecnológico facilita o surgimento de empresas por meio da redução de custos de criação da empresa (papel incubador do parque).

Corrobora Araújo e Villas Boas (2013), afirmando que as incubadoras são reconhecidas como elementos importantes que promovem a inovação, o empreendedorismo e 0 desenvolvimento econômico.

Segundo Berni et al. (2015), as universidades têm conquistado maior destaque para o setor produtivo, na medida em que contribuem para a geração de novos conhecimentos, auxiliando no processo de inovação das empresas por meio da pesquisa. Assim, as universidades tornaram-se agentes indutores à inovação, promovendo a interação entre ambiente acadêmico e setor produtivo, viabilizando inclusive o acesso a laboratórios e ao capital humano (TAVARES, 2010; SOUZA et al., 2003; ARAÚJO; ONUSIC, 2014).

Perspectivas em Gestão \& Conhecimento, João Pessoa, v. 8, n. 2, p. 126-144, mai./ago. 2018. 
Portanto, o tópico verificado da relação das empresas com as instituições de ensino e centros de pesquisa, reforça a ideia de Raposo e Serrasqueiro (2005, p. 102), de que cabe à universidade a importante função de estimular o aparecimento de empresas, seja de modo direto pelo efeito dinamizador do conhecimento gerado, seja de modo indireto pelos fluxos financeiros que movimenta.

De acordo com os empresários entrevistados, o processo de inovação está altamente relacionado com o networking da empresa, propiciado pelos recursos fornecidos pela incubadora. Portanto, foi unânime dentre os entrevistados que o fato de pertencer à incubadora do ParqTec facilita o estabelecimento de novos contatos e a criação de uma carteira de clientes, que trazem aos empreendedores as expectativas e necessidades do mercado consumidor.

Os resultados confirmam Amorim et al. (2004), para quem o fortalecimento do capital social, que se relaciona com o networking da organização, está condicionado a criação de uma rede de cooperação entre atores e instituições. Na medida em que as ações deixam de ser cada vez menos individualizadas e tornam-se mais coletivizadas, torna-se necessária a constituição de uma força de coordenação das diversas ações de modo a garantir a formação de sinergias que possam garantir o alcance dos objetivos desejados.

Andrade et al. (2016) conclui que as incubadoras desempenham um papel socioeconômico importante, visto que são capazes de reunir em um mesmo ambiente diversas facilidades, desde auxílio financeiro até apoio administrativo e estrutura física. Ou seja, os empreendimentos têm acesso à infraestrutura para realizar suas atividades e orientações na fase de desenvolvimento de suas empresas.

Estas facilidades favorecem o desenvolvimento de novas tecnologias, o fortalecimento de novas spin-offs e cria um ambiente propício ao empreendedorismo, que, por sua vez, contribui para a competitividade e desenvolvimento da economia local (RAUPP; BEUREN, 2011; OECD, 2010).

Considerando as redes identificadas, compartilha-se o conceito de Wasserman e Faust (1994), Scott (2000), Sacomano Neto e Truzzi (2004), Mizruchi (2006) e Kilduff e Tsai (2007), de que, morfologicamente, toda rede é composta pelos nós (atividades ou empresas), posições na estrutura, ligações e fluxos entre os atores.

A partir da análise morfológica da rede é possível compreender como as empresas conseguem acessar recursos e informações de outras organizações, ratificando Zaneti et al. (2013), que afirmam que as empresas em rede se complementam umas às outras nos aspectos técnicos e mercadológicos e decidem apoiar-se mutuamente em prioridade.

Os recursos foram identificados a partir de categorias pré-definidas, a saber: recursos humanos, físicos, financeiros, tecnológicos, reputacionais e organizacionais, confirmando a presença destas categorias, conforme defendem Grant (1991) e Hill e Jones (1996), que os recursos referem-se aos meios físicos, financeiros, humanos, tecnológicos e organizacionais e à reputação da empresa, podendo se dividir em tangíveis, tais como terrenos, edifícios e máquinas, e intangíveis, tais como marca, reputação da empresa, confiança dos clientes, informações sobre clientes e concorrentes, patentes e know-how.

Lazzari et al. (2014) asseveram que a identificação de recursos estratégicos e especificidade de ativos são os fatores que explicam o sucesso da empresa. Na percepção de Barney e Hesterly (2007), para gerar vantagem competitiva os recursos precisam ser valiosos, raros, difíceis de imitar e a organização deve estar preparada para integrá-los, explorá-los e oferecer suporte via atividades, operações, políticas e procedimentos. Os dizeres de Barney e Hesterly (2007) também salientam que os recursos e capacidades que são valiosos para a empresa são considerados as suas forças. Desta forma, os resultados verificados condizem com a teoria, de modo que as empresas buscam as alianças estratégicas como forma de alcançar os recursos valiosos de outras empresas.

Perspectivas em Gestão \& Conhecimento, João Pessoa, v. 8, n. 2, p. 126-144, mai./ago. 2018. 
Considerando os recursos identificados, a partir das categorias já indicadas, analisando as entrevistas da incubadora e das empresas, pode-se dizer que todas apresentam particularidades e especialidades que fomentam a criação de alianças estratégicas, tanto entre as empresas como entre a incubadora e as empresas.

Citado por todas as empresas, os recursos da incubadora como apoio e estrutura física, networking com empresas e clientes e acesso facilitado a agências de fomento, atraem os empreendedores para instalar suas empresas nestes ambientes propícios. Além disso, o ParqTec dispõe de programas que auxiliam as empresas, como o Parqtec.edu (voltado para a formação, treinamento e especialização em gestão empresarial); o Parqtec.ipd (desenvolvimento de pesquisas tecnológicas e promoção de atividades de desenvolvimento regional); Parqtec.parks (atração de investimentos e pessoas talentosas, motivadas e empreendedoras); Parqtec.net (acesso à rede de relacionamentos, assessoria e consultoria, desenvolvimento de produtos, treinamento e capacitação) e, Parqtec.org (entidade pioneira para institucionalizar a transferência de tecnologia da academia para o setor produtivo.

Portanto, as redes de cooperação têm um papel fundamental para que as empresas consigam acessar e alcançar recursos, tecnologias, informação, conhecimento, reforçando o conceito de que a colaboração é um importante facilitador dos processos de inovação, de obtenção de tecnologia e acesso a mercados específicos. A colaboração permite o acesso a desenvolvimentos complementares de produção, recursos e produtos, redução de riscos financeiros e políticos, além de vantagens competitivas (JOHANSEN; COMSTOCK; WINROTH, 2005).

A cooperação instaura-se para cumprir com um objetivo comum entre os envolvidos e sucede-se quando indivíduos, defrontados com um problema, unem-se em prol da resolução das dificuldades enfrentadas, de modo que são atribuídas tarefas a cada um (TEIXEIRA et al., 2007).

Tavares e Castro (2012) destacam que a condição de cooperar é considerada como elemento-chave nas relações interorganizacionais. Os pressupostos e elementos de cooperação são a base para a idealização das redes, de forma que as empresas que a compõe veem na supracitada cooperação uma saída para alcançar resultados mais satisfatórios no mercado, além da expectativa de aperfeiçoar ou angariar recursos (TAVARES; CASTRO, 2012; WEGNER; MAEHLER, 2012).

É percebido, então, vantagens atribuídas às empresas que se inserem em uma rede de cooperação, tais como: ganhos de escala e poder de mercado; condições para aprendizagem e inovação; redução de custos e riscos, entre outros (VERSCHOORE; BALESTRIN, 2008).

\section{CONSIDERAÇÕES FINAIS}

Nesta pesquisa foram realizadas entrevistas com três empreendedores de empresas incubadas na Incubadora Softnet do ParqTec e com o gerente da Incubadora Softnet.

A presente pesquisa deixou evidente a intensa relação entre recursos disponíveis e redes sociais de cooperação estabelecidas, uma vez que a maior disposição de recursos impulsiona as empresas a buscarem a criação de redes, levando a percepção de que a cooperação propicia vantagens que dificilmente seriam alcançadas isoladamente, compartilhando a ideia de Gulati, Nohria e Zaheer (2000), de que as redes de empresas têm papel estratégico, pois permitem que a empresa participante tenha acesso à informação, recursos, mercados e tecnologias, com vantagens de aumentar seus conhecimentos e obter economias de escala e escopo. Além disso, contribuiu para a compreensão do ambiente organizacional no qual estão inseridas as empresas de base tecnológica incubadas e a incubadora Softnet.

Perspectivas em Gestão \& Conhecimento, João Pessoa, v. 8, n. 2, p. 126-144, mai./ago. 2018. 
Quanto ao objetivo proposto por este trabalho, pode-se dizer que foi atingido, uma vez que se identificou e analisou-se as redes e os recursos da incubadora de empresas Softnet e das empresas Cubo TI, Onion e Neolnfinito, colaborando e auxiliando possíveis novos empreendedores a se estabelecer em incubadoras de empresas.

Portanto, com a presente pesquisa, considerando a colaboração existente entre os atores envolvidos na incubadora com as instituições e centros de ensino e pesquisa, além da relação com outras empresas incubadas, conclui-se que o processo de inovação tecnológica é altamente facilitado pelas redes sociais através do networking e da cooperação, de modo que os resultados alcançados pelas organizações em rede são superiores aos frutos obtidos individualmente pelas empresas.

O estudo sugere fortemente a necessidade de prosseguir com a discussão de redes e recursos em ambientes de inovação como as incubadoras de empresas. As sugestões para estudos futuros abrangem: a realização de estudo em outras empresas de outras incubadoras, tanto do mesmo município como em outros; o desenvolvimento de um estudo comparativo entre empresas incubadas e empresas não-incubadas buscando os prós e contras em fazer desses ambientes inovadores; realizar um estudo com empresas graduadas para verificar as vantagens e desvantagens em ter surgido em uma incubadora de empresas; além da elaboração de estudo focado nas falhas e dificuldades dos programas governamentais para estímulo à inovação, evidenciado nesta pesquisa pela ausência de relações com agentes políticos.

\section{REFERÊNCIAS}

ACIOLI, Sonia. Redes Sociais e teoria social: revendo os fundamentos do conceito. Informação \& Informação, Londrina, v.12, n.esp, p.1-12, 2007.

AMIT, Rafael; SCHOEMAKER, Paul J. H. Strategic assets and organizational rents. Strategic Management Journal, Local, v. 14, p. 33-46, jan. 1993.

AMORIM, Mônica A.; MOREIRA, Maria V. C.; IPIRANGA, Ana S. R. A construção de uma metodologia de atuação nos Arranjos Produtivos Locais (APLS) no estado do Ceará: um enfoque na formação e fortalecimento do capital social e da governança. Revista Internacional de Desenvolvimento Local, Campo Grande, MS, v. 6, n. 9, p. 25-34, set. 2004.

ANDINO, Byron Fabricio Acosta; FRACASSO, Edi Madalena. Efetividade do processo de incubação de empresas. In: ENCONTRO NACIONAL DA ANPAD, 24., 2005, Brasília. Anais... Brasília, 2005. CDROM.

ANDRADE, Claudia C.; PASIN, Luiz Eugênio V.; OTTOBONI, C.; MINEIRO, Andrea A. C. Análise do capital institucional na incubadora de empresas de base tecnológica: um estudo de caso do município de Itajubá - MG. Revista de Administração, Contabilidade e Economia da FUNDACE, Ribeirão Preto, SP, v. 7, n. 1, 2016.

ANPROTEC, Associação Nacional de Entidades Promotoras de Empreendimentos Inovadores. Análise e Proposições sobre incubadoras de Empresas no Brasil - relatório técnico. Brasília: MCTI, 2012.

ARAÚJO, Cíntia Möller; VILLAS BOAS, Giovanna. Políticas públicas e incubação de empresas: o caso do estado de São Paulo. Revista Ciências Administrativas, Fortaleza-CE, v. 19, n.02, p. 507-535, jul/dez, 2013.

Perspectivas em Gestão \& Conhecimento, João Pessoa, v. 8, n. 2, p. 126-144, mai./ago. 2018. 
ARAÚJO, Cíntia Möller; ONUSIC, Luciana Massaro. A Incubadora de Empresas de Osasco: uma proposta de gestão técnica-científica-cidadã envolvendo a Universidade Federal de São Paulo Unifesp e a Prefeitura de Osasco (São Paulo). Interfaces - Revista de Extensão da UFMG, Belo Horizonte, v. 2, n. 3, p. 77-94, jul./dez. 2014.

BALESTRIN, Alsones; VERSCHOORE, Jorge Renato; REYES JR., Edgar. O campo de estudo sobre redes de cooperação interorganizacional no Brasil. Revista de Administração Contemporânea (RAC), Curitiba, v. 14, n. 3, p. 458-477, 2010.

BALESTRIN, Alsones; VARGAS, Lilia Maria. A dimensão estratégica das redes horizontais de PMEs: teorizações e evidências. Revista de Administração Contemporânea - RAC, Curitiba-PR, v. 8, p. 203-227. 2004.

BARABÁSI, Albert-Lászlo. Linked: how everything is connected to everything else and what it means for business, science and everyday life. New York: Plume, Penguin Group, 2003.

BARDIN, Laurence. Análise de conteúdo. São Paulo: Edições 70, 2011.

BARNEY, Jay B. Firm resources and sustained competitive advantage. Journal of Management, Great Britain, v.17, n.1, p.99-120, mar. 1991.

BARNEY, Jay B; HESTERLY, William S. Administração Estratégica e Vantagem Competitiva: casos brasileiros. São Paulo: Pearson, 2007.

BERNI, Jean Carlo Albiero; GOMES, Clandia Maffini; PERLIN, Ana Paula; KNEIPP, Jordana Marques; FRIZZO, Kamila. Interação universidade-empresa para inovação e a transferência de tecnologia. Revista Gestão Universitária na América Latina, Florianópolis-SC, v. 8, n.2, p. 258277, mai. 2015.

CALDERA, Aida; DEBANDE, Olivier. Performance of Spanish universities in technology transfer: an empirical analysis. Research Policy, v. 39, n. 9, p. 1160-1173, 2010.

CHASSAGNON, Virgile. Consummate cooperation in the network-firm: Theoretical insights and empirical findings. European Management Journal, Elsevier, v. 32, n.2, p. 260-274, 2014.

CASSELL, Catherine; SYMON, Gillian. Qualitative research in work contexts. In: CASSELL, C; SYMON, G. Qualitative Methods in Organizational Research. London: Sage Publications, 1995, p. 1-13.

CASTELLS, Manuel. A sociedade em rede. São Paulo: Paz e Terra, v. 1, 1999.

. Material for an Exploratory Theory of the Network Society. British Journal of Sociology, London, v. 51, n. 1, p. 5-24, Jan.-Mar, 2000.

The Internet Galaxy: Reflections on the Internet, Business, and Society. Oxford: Oxford University Press, 2001.

CASTILLA, Emilio J.; HWANG, Hokyu; GRANOVETTER, Ellen; GRANOVETTER, Mark. Social networks in silicon valley. In C. M. Lee, W. F. Miller, M. G. E. Hancock, \& H. S. Rowen (Eds.), The silicon valley edge. Stanford: Stanford University Press, p. 218-247, 2000.

CHENG, Lin Chih et al. Plano tecnológico: um processo auxiliar ao desenvolvimento de produtos de empresas de base tecnológica de origem acadêmica. Locus Científico, v. 1, n. 2, p. 32-40, 2007.

CÔRTES, Mauro Rocha; PINHO, Marcelo; FERNANDES, Ana Cristina; SMOLKA, Rodrigo Bustamante; BARRETO, Antonio Luiz C. M. Cooperação em empresas de base tecnológica: uma

Perspectivas em Gestão \& Conhecimento, João Pessoa, v. 8, n. 2, p. 126-144, mai./ago. 2018. 
primeira avaliação baseada numa pesquisa abrangente. São Paulo em Perspectiva, São PauloSP, v. 19, n. 1, p. 85-94, jan./mar. 2005.

D'OLIVEIRA, José Luiz P.; REZENDE GUEDES, Leonardo Guerra de; PASQUALETTO, Antonio; SILVA, Solange; ROCHA, Marcelo Lisboa. Business Cooperation Networks: Risks and Benefits. International Journal of e- Education, e-Business, e-Management and e-Learning, v. 6, n. 2, p.120, 2016.

DUARTE, Rosália. Entrevistas em pesquisas qualitativas. Educar em Revista. Universidade Federal do Paraná, Curitiba, n. 24, p. 213-225, 2004.

FEIJÓ, Rodrigo Medeiros; ZUQUETTO, Rovian Dill. Cooperar para sobreviver e crescer: análise da rede de cooperação redemac. Revista de Administração Mackenzie, São Paulo-SP, v. 15, n. 3, p. 21, 2014.

FERREIRA, Toniel; VITORINO FILHO, Valdir Antonio. Teoria de redes: uma abordagem social, Revista Conteúdo, São Paulo, v. 1, n. 3, 2010.

GIGLIO, Ernesto M.; SACOMANO NETO, Mário. Ensaio sobre o Paradigma da Sociedade em Rede: Aspectos Teóricos, Metodológicos e Aplicativos. Revista de Administração da Unimep, v. 14, n. 1, p. 30-53, 2016.

GRANT, Robert M. The resource-based theory of competitive advantage: implications for strategy formulation. California Management Review, Spring, p. 114-135, 1991.

GULATI, Ranjay; NOHRIA, Nitin; ZAHEER, Akbar. Strategic networks. Strategic Management Journal, v. 21, p. 203-215, 2000.

HILL, Charles W. L.; JONES, Gareth R. Administración estratégica: un enfoque integrado, Santafé de Bogotá: McGraw-Hill, 1996.

JESUS, Marcos Junio Ferreira; MACHADO, Hilka Vier. A importância das redes sociais ou networks para o empreendedorismo. Revista eletrônica de Administração - FACEF, Edição 14, vol. 13. 2009.

JOHANSEN, Kerstin; COMSTOCK, Mica; WINROTH, Mats. Coordination in collaborative manufacturing mega-networks: a case study. Journal of Engineering and Technology Management, v. 22, p. 226-244, 2005.

KILDUFF, Martin; TSAl, Wenpin. Social Networks and Organizations. Sage Publications: London, 2007.

KIMURA, Herbert; TEIXEIRA, Maria Luisa Mendes; GODOY, Arilda Schmidt. Redes sociais, valores e competências: simulação de conexões. Revista de Administração Contemporânea RAC, Curitiba, Edição Especial, p. 42-57. 2004.

KLOTZLE, Marcelo Cabus. Alianças estratégicas: conceito e teoria. Revista de Administração Contemporânea - RAC, Curitiba, v. 6, n.1, jan./abr. 2002.

LAZZARI, Fernanda; SARATE, João Alberto; GONÇALVES, Roberto Birch; VIEIRA, Guilherme Borges Bergmann. Competitive advantage: the complementarity between TCE and RBV. Revista de Administração FACES Journal, Belo Horizonte, v. 13, n. 3, p. 86-103, 2014.

LEE, Seungyoon; MONGE, Peter. The coevolution of multiplex communication networks in organizational communities. Journal of Communication, v. 61, n. 4, p. 758-779, 2011.

LEITE, Emanuel. Empreendedorismo, inovação e incubação de empresas: Lei de Inovação. Recife: Bagaço, 2006.

Perspectivas em Gestão \& Conhecimento, João Pessoa, v. 8, n. 2, p. 126-144, mai./ago. 2018. 
MANZINI, Eduardo José. Considerações sobre a elaboração de roteiro para entrevista semiestruturada. In: MARQUEZINE, M. C.; ALMEIDA, M. A.; OMOTE, S. (Org.). Colóquios sobre pesquisa em educação especial. Londrina: Eduel, p.11-25, 2003.

Entrevista semi-estruturada: análise de objetivos e de roteiros. In: SEMINÁRIO INTERNACIONAL DE PESQUISA E ESTUDOS QUALITATIVOS, 2, A pesquisa qualitativa em debate, Bauru, 2004. Anais..., Bauru: SIPEQ, 2004. 1 CD.

MIZRUCHI, Mark S. Análise de redes sociais: avanços recentes e controvérsias atuais. Revista de Administração de Empresas, São Paulo, v. 46, n. 3, p. 72-86, 2006.

MÜLLER-SEITZ, Gordon. Leadership in interorganizational networks: a literature review and suggestions for future research. International Journal of Management Reviews, v. 14, n. 4, p. 428-433, 2011.

NOHRIA, Nitin; ECCLES, Robert G. Networks and organizations. Boston: Harvard Business School Press, 1992.

NORMAN, Aguilar Gallegos; ALEJANDRO, Velázquez. Álvarez. Manual introdutório à Análise de Redes Sociais. UAEM - Universidad Autónoma Del Estado de México, 2005.

OECD - ORGANIZATION FOR ECONOMIC CO-OPERATION AND DEVELOPMENT. Technology incubators, $2010 . \quad$ Disponível em: $<$ https://www.innovationpolicyplatform.org/sites/default/files/rdf imported documents/Tec hnologylncubators.pdf $>$. Acesso em: 28 de novembro 2014.

PARQTEC. 2015. Disponível em <http://www.parqtec.com.br>. Acesso em: 10 de dezembro de 2015.

PETERAF, Margaret. The cornerstones of competitive advantage: a resource-based view. Strategic Management Journal, v. 14, n. 3, p. 179-191, mar. 1993.

POLETTO, Carlos A.; DUARTE, Maria A.; MATA, Wilson. Gestão compartilhada de P\&D: o caso da Petrobras e a UFRN. Revista de Administração Pública, Rio de Janeiro, v. 45, n. 4, p. 10951117, set./out. 2011.

RAPOSO, Mário L.; SERRASQUEIRO, Zélia. A universidade e o desenvolvimento regional. Cadernos de Economia, ano XVIII, n. 71, p. 100-104, abr/jun, 2005.

RAUPP, Fabiano Maury; BEUREN, Ilse Maria. Perfil do suporte oferecido pelas incubadoras brasileiras às empresas incubadas. REAd. Revista Eletrônica de Administração, Porto Alegre, v. 17, n. 2, p. 330-359, 2011.

REA, Louis M.; PARKER, Richard A. Metodologia da pesquisa: do planejamento à execução. São Paulo: Pioneira, 2000.

SACOMANO NETO, Mário; TRUZZI, Oswaldo Mário Serra. Configurações estruturais e relacionais da rede de fornecedores: uma resenha compreensiva. Revista de Administração RAUSP, v. 39, n. 3, p. 244-263, 2004.

SCOTT, John P. Social Network Analysis: A Handbook. Sage Publications: London, 2000.

SEIDMAN, Irving. Interviewing as qualitative research. 2.nd. New York: Teachers College Press, 1988.

SEGATTO-MENDES, Andrea Paula. Análise do processo de cooperação tecnológica universidade - empresa: um estudo exploratório. 1996. 175 f. Dissertação (Mestrado em Administração) - Universidade de São Paulo, São Paulo, 1996.

Perspectivas em Gestão \& Conhecimento, João Pessoa, v. 8, n. 2, p. 126-144, mai./ago. 2018. 
SILVEIRA, Lisilene Mello da. A influência das redes de cooperação no desenvolvimento de iniciativas de sustentabilidade. 2016. 156 f. Dissertação de Mestrado. Pontifícia Universidade Católica do Rio Grande do Sul, Porto Alegre-RS, 2016.

SOUZA, Maria Carolina de Azevedo Ferreira de; AZEVEDO, Alessandra de; OLIVEIRA, Luiz José Rodrigues de; BALDEÓN, Nguyen Tufino. Incubadora Tecnológica de Cooperativas - ITCP $\mathrm{x}$ Incubadora de Empresas de Base Tecnológica - IEBT - Diferenças e semelhanças no processo de Incubação. Revista ibero-americana de ciência, tecnologia, sociedade e innovación, Madri, n. 6, 2003.

SOARES, Wesley Braga; WEGNER, Douglas; Dolci, Pietro Cunha. Fusão Como Estratégia de Crescimento de Redes de Cooperação Empresarial: Um Estudo de Caso em uma Rede de Farmácias. Iberoamerican Journal of Strategic Management, v. 15, n. 1, p. 83-96, 2016.

TAVARES, Walkyria Menezes Leitão. Parques, Pólos tecnológicos e incubadoras: balanço da experiência brasileira e de outros países. Cadernos Aslegis 9, 2010.

TAVARES, Wellington; CASTRO, Cleber Carvalho de. Relações Interorganizacionais no estabelecimento de uma aglomeração produtiva. Revista de Administração FACES Journal, Belo Horizonte, v. 11, n. 4, p. 31-50, out.- dez. 2012.

TEIXEIRA, Enise Barth; VITCEL, Marlise Sozio; BEBER, Marlise Costa. Cooperação Estratégica, Redes de Cooperação e Desenvolvimento Regional: o caso Unijuí/Sedai. Desenvolvimento em Questão, Editora Unijuí, ano 5, n. 10, p. 187-210, jul. - dez., 2007.

VERSCHOORE, Jorge Renato. Redes de cooperação interorganizacionais: a identificação de atributos e benefícios para um modelo de gestão. 2006. 253 f. Tese de doutorado. Universidade Federal do Rio Grande do Sul, Porto Alegre-RS, Brasil, 2006.

VERSCHOORE, Jorge Renato; BALESTRIN, Alsones. Ganhos competitivos das empresas em redes de cooperação. Revista de Administração Eletrônica, São Paulo, v.1, n.1, jan.-jun., 2008.

ZANETI, Gislaine Barbosa; FUSCO, José Paulo Alves; ROCHA, Regina Ferreira da. Análise comparativa de redes interfirmas de instituições de ensino superior. Revista Eletrônica Produção \& Engenharia, v. 4, n. 2, p. 395-402, Jan./Jun. 2013.

WASSERMAN, Stanley; FAUST, Katherine. Social network analysis. Cambridge: Cambridge University Press, 1994.

WEGNER, Douglas; MAEHLER, Alisson Eduardo. Desempenho de empresas participantes de rede interorganizacionais: analisando a influência do capital social e da capacidade absortiva. Revista Gestão e Planejamento, Salvador, v. 13, n. 2, p. 191-211, maio-ago. 2012.

WERNERFELT, Birger. A resource-based view of the firm. Strategic Management Journal. v. 5, p. 171-180, 1984.

YIN, Robert K. Estudo de caso: planejamento e métodos. Porto Alegre: Editora Bookman, 2001.

Artigo recebido em 01/03/2017 e aceito para publicação em 30/05/2018

Perspectivas em Gestão \& Conhecimento, João Pessoa, v. 8, n. 2, p. 126-144, mai./ago. 2018. 


\section{APÊNDICE A - Roteiro de entrevista para o gestor da Incubadora de Empresas}

1) Nome do entrevistado;

2) Cargo do entrevistado;

3) Explique o histórico e o surgimento da incubadora;

4) Qual é a infraestrutura fornecida pela incubadora às empresas;

5) O que é necessário para uma empresa se instalar na incubadora;

6) Quais as instituições que mantém relacionamento com a incubadora e qual é natureza desta relação;

7) Quais os principais atores participantes do ambiente da incubadora;

8) Qual é a relação entre a incubadora e as universidades USP e UFSCar;

9) Qual é a relação entre a incubadora e centros de pesquisas como a Embrapa;

10) Qual é a relação entre a incubadora e os atores políticos;

11) Quais os recursos que a incubadora possui;

12) Quais as ações da incubadora para estimular o desenvolvimento de acordos de cooperação das empresas incubadas.

\section{APÊNDICE B - Roteiro de entrevista para o gestor/proprietário das empresas}

1) Nome do entrevistado;

2) Cargo do entrevistado;

3) Explique o histórico e o surgimento da empresa;

4) Relações institucionais (públicos e privadas) que apoiaram o surgimento da empresa;

5) Qual o número de funcionários com formação específica oriundos de instituições de ensino;

6) Quais são os principais clientes da empresa;

7) Há parcerias e cooperação para o desenvolvimento de novos produtos;

8) Principais agentes políticos no nível federal, estadual e local com os quais a empresa mantém relação;

9) Qual a natureza desta relação com os agentes políticos;

10) Principais universidades em cooperação e natureza desta cooperação;

11) Principais pesquisadores e resultados desta parceria;

12) Descreva a relação com as associações de classe / sindicatos;

13) Quais os fluxos gerados a partir da conexão da empresa com a incubadora, com as universidades, centros de pesquisa, agentes políticos (conhecimento, tecnologia, profissionais, estrutura física etc);

14) Quais os objetivos em estabelecer redes de cooperação;

15) Descreva as vantagens com cada associação estabelecida entre a empresa e os atores ambientais;

16) A empresa participa de ações coletivas como, por exemplo, feiras;

17) Qual a importância das redes de relações para o processo de inovação tecnológica da empresa;

18) Quais os recursos que a empresa possui;

19) Quais as relações estabelecidas buscando o aproveitando dos recursos. 